¿PS

\title{
Torque and Flux Ripple Minimization of Induction Motor Using Hybrid Neuro Fuzzy Controller
}

\author{
V. Sakthi ${ }^{1}$, A. Sivasubramanian ${ }^{2}$, \\ Research Scholar/EEE ${ }^{l}$, SCSVMV University ${ }^{l}$, Kanchipuram $^{l}$, India $^{l}$ \\ Principal $^{2}$, Mount Zion College of Engineering ${ }^{2}$, Pathanamthitta ${ }^{2}$, India ${ }^{2}$ \\ *Corresponding author E-mail: vsakthi.me@gmail.com
}

\begin{abstract}
This paper proposed to design, implementation and simulation of Direct Torque Control of Induction Motor drive system is to minimize stator current distortion, electromagnetic torque and flux ripples. In this paper, Hybrid Neuro-Fuzzy Controller is proposed to replace the conventional PI torque and flux controller to achieve desired torque and flux with zero steady state error and also with good dynamic fast response. Neuro-Fuzzy based torque and flux controllers are designed to optimize the stator voltages in d-q reference frame that applied to Direct Torque Control. Simulation and the performance of the proposed Hybrid NFC are analyzed. Simulation results showed that a significant improvement in dynamic torque and speed response in both steady and transient states and also a considerable reduction in torque and flux minimization compared to the other AI techniques.
\end{abstract}

Keywords: Direct Torque Control (DTC); Field Oriented Control (FOC); Fuzzy Logic Controller (FLC); Induction Motor (IM); Neuro Fuzzy Controller (NFC).

\section{Introduction}

Induction motor drives with cage type machines have been the workhorse in industry for variable speed applications in a wide power range that covers from fractional horsepower to multimegawatts. These applications include pumps and fans, paper and textile mills, subway and locomotive propulsions, electric and hybrid vehicles, machine tools and robotics, home appliances, neat pumps and air conditioners, rolling mills, wind generation systems, etc., In addition to process control, the energy saving aspect of variable frequency drives is getting lot of attention nowadays. The main reasons for this complexity are the need of variable frequency, harmonically optimum converter power supplies, the complex dynamics of ac machines, machine parameter variations, and the difficulties of processing feedback signals in the presence of harmonics. In last two decades the use of AC drives with DTC technique have gradually increased due to its advantages over the Field Oriented Control (FOC) techniques, good dynamic performance, precise and quick response of stator flux and electromagnetic torque, robust against machine parameter variations, no current

control loop and simplicity of the algorithm [3].A classical or conventional DTC drive system, which is based on a fixed hysteresis bands for both torque and flux controllers, suffers from a varying switching frequency, which is a function of the motor speed; stator fluxes and stator voltage; it is also not constant in steady state. Variable switching frequency is undesirable at low speed operation; an appreciable level of noise is present which is mainly due to the low inverter switching frequency. The high frequency is limited by the switching characteristics of the power semiconductor devices. Therefore, there will be large torque ripples and distorted wave forms in currents and fluxes. Several solutions have been proposed to keep constant switching frequency like in [2-8]. In order to improve the dynamic performance of the classical DTC scheme, a new modified DTC based Neuro Fuzzy Controller (NFC) is proposed. In this technique is to ensure a constant switching frequency and the use of NFC is to obtain a decoupled between torque and flux.

This present paper deals the development of a Neuro Fuzzy Direct Torque Control (NFDTC), expected to improve the dynamic performance compared to the Conventional DTC system. To overcome the disadvantages of the Classical DTC method such as, starting problems, distorted current waveform, Variable switching frequency, high torque and flux ripples and sluggish response. This new proposed NFDTC system is designed, proved by means of simulation in MATLAB/SIMULINK. This paper has Section 2 DTC basic concepts and its principles; Section 3 Torque and Stator flux control, Section 4 Basic switching table and selection of voltage vectors, Section 5 Hybrid Neuro Fuzzy Direct Torque Controller and Simulation results, Section 6 Conclusion and Future work.

\section{$1.1 \quad$ Literature review}

Many researchers have investigated on DTC methods to improve the performance of induction motor. They are as follows:

(i) Achievement of torque ripples reduction by switching table modification, by Noguchi etal 1999 .

(ii) Torque ripples reduction by increased number of generated inverter switching states, by Domenico Casadei et al 2002.

(iii) Deducing RMS torque ripple equation for torque ripple reduction, by Kyo-Beum Lee et al 2002. 
(iv) Dead-beat control for torque ripples reduction, by Sheng-Ming Yang et al 2002.

(v) DTC with constant switching frequency for torque ripple reduction, by Buja et al 2004.

\subsection{DTC basic concepts and its principles}

In the mid 1980s, an advanced Scalar Control technique, known as Direct Torque and Flux Control (DTFC or DTC) or Direct Selfcontrol (DSC) was introduced for voltage-fed PWM inverter drives. The DTC proposed by Takashi and M. Depenbrock for variable load

and speed asynchronous motor drives. It was a good alternative to the other type of vector control which known as FOC [5] due to some well known advantages, such as simple control structure, robust and fast torque response without co-ordinate transformation PWM pulse generation and current regulators moreover, DTC minimizes the use of motor parameters. Besides these advantages, DTC scheme [6] still had some disadvantages like high torque and current ripples, possible problems during starting and low speed operation, variable switching frequency.

\subsection{Torque expression with stator and rotor fluxes}

The torque expression given in equation is

$\mathrm{T}_{\mathrm{e}}=\frac{3}{2} \frac{P}{2}\left(\overline{\psi_{\mathrm{ds}}} \mathrm{i}_{\mathrm{qs}}^{\mathrm{s}}-\psi_{\mathrm{qs}}{ }^{\mathrm{s}} \mathrm{i}_{\mathrm{ds}}{ }^{\mathrm{s}}\right)$

The above equation can be expressed in the vector form is

$\overline{\mathrm{T}}_{\mathrm{e}}=\frac{3}{2} \frac{P}{2} \bar{\psi}_{\mathrm{s}} \mathrm{X} \overline{\mathrm{i}}_{\mathrm{s}}$

Where $\overline{\psi_{\mathrm{s}}}=\psi_{\mathrm{ds}}^{\mathrm{s}}-\mathrm{j} \psi_{\mathrm{qs}}^{\mathrm{s}}$ and $\overline{\mathrm{I}}_{\mathrm{s}}=\mathrm{i}_{\mathrm{qs}}{ }^{\mathrm{s}}-\mathrm{i}_{\mathrm{ds}}{ }^{\mathrm{s}}$. In this equation, $\overline{\mathrm{I}}_{\mathrm{s}}$ is to be replaced by rotor flux $\overline{\psi_{\mathrm{r}}}$. In the complex form, $\overline{\psi_{\mathrm{s}}}$ and $\overline{\psi_{\mathrm{r}}}$ can be expressed as functions of currents as

$\overline{\Psi \mathrm{s}}=\mathrm{L}_{\mathrm{s}} \overline{\mathrm{I}}_{\mathrm{s}}+\mathrm{L}_{\mathrm{m}} \overline{\mathrm{I}}_{\mathrm{r}}$

$\overline{\Psi_{\mathrm{S}}}=\operatorname{Lr} \overline{\mathrm{I}}_{\mathrm{r}}+\mathrm{L}_{\mathrm{m}} \overline{\mathrm{I}}_{\mathrm{s}}$

Eliminating $\mathrm{I}_{\mathrm{s}}$ from Equation (3.3), we get

$\overline{\Psi_{\mathrm{S}}}=\frac{L m}{\mathrm{Lr}} \overline{\psi_{\mathrm{r}}}+\mathrm{L}_{\mathrm{S}}^{\prime} \overline{\mathrm{I}_{\mathrm{S}}}$

Where $\mathrm{L}_{\mathrm{s}}{ }^{\prime}=\mathrm{L}_{\mathrm{s}} \mathrm{I}_{\mathrm{r}}-\mathrm{L}_{\mathrm{m}}^{2}$. The corresponding expression of $\mathrm{I}_{\mathrm{s}}$ is

$$
\overline{\mathrm{I}_{\mathrm{s}}}=\frac{1}{\mathrm{Ls} \prime} \overline{\psi_{\mathrm{s}}}-\frac{L m}{\mathrm{LrLs} \prime} \overline{\psi_{\mathrm{r}}}
$$

Substituting Equations (3.6) in (3.1) and simplifying yields

$\mathrm{T}_{\mathrm{e}}=\frac{3}{2} \frac{P}{2} \frac{L m}{\mathrm{LrLs} \prime} \overline{\psi_{\mathrm{r}}} \mathrm{X} \overline{\psi_{\mathrm{s}}}$

That is, the magnitude of torque is

$\mathrm{T}_{\mathrm{e}}=\frac{3}{2} \frac{P}{2} \frac{L m}{\operatorname{LrLs} \prime}\left|\psi_{\mathrm{r}}\right|\left|\psi_{\mathrm{s}}\right| \sin \gamma$

Where, $\gamma$ is the angle between the fluxes. Figure shows the phasor diagram for equation (3.7), indicating the vectors $\overline{\psi_{\mathrm{s}}}, \overline{\psi_{\mathrm{r}}}$ and $\overline{\mathrm{I}}_{\mathrm{s}}$ for positive developed torque. If the rotor flux remains constant and the stator flux is changed incrementally by stator voltage $\bar{V}_{\mathrm{s}}$ as shown, and the corresponding change of $\gamma$ angle is $\Delta \gamma$, the incremental torque $\Delta \mathrm{T}_{\mathrm{e}}$ expression is given as

$\Delta \mathrm{T}_{\mathrm{e}}=\frac{3}{2} \frac{P}{2} \frac{L m}{\operatorname{LrLs} \prime}\left|\psi_{\mathrm{r}}\right|\left|\overline{\psi_{\mathrm{s}}}+\Delta \overline{\psi_{\mathrm{s}}}\right| \sin \gamma$

\section{2 \\ Basic switching table and selection of voltage} vectors

The basic working principle of switching table of DTC concept [7] is shown in figure.3. The reference stator flux $\psi_{\text {sref }}$, and torque $\mathrm{T}_{\text {eref }}$ are compared with the actual value of $\psi_{\mathrm{s}}$ and $\mathrm{T}_{\mathrm{e}}$ in hysteresis flux and torque controller respectively. The hysteresis flux controller is a two-level comparator while the hysteresis torque controller is a three level comparator.

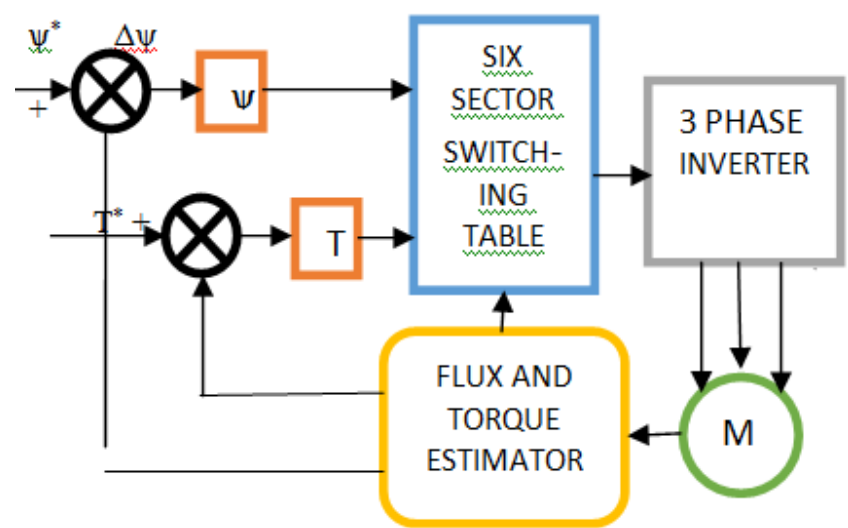

Figure 3: shows block diagram of DTC Switching table concept

The output signal of hysteresis flux controller is define as given below

$$
\begin{gathered}
\psi_{\text {serr }}=1, \text { for } \psi_{\mathrm{s}}<\psi_{\text {sref }}-\mathrm{H}_{\psi} \\
\psi_{\text {serr }}=-1, \text { for } \psi_{\mathrm{s}}<\psi_{\text {sref }}+\mathrm{H}_{\psi}
\end{gathered}
$$

and output signal of hysteresis torque controller are define as given below

Where $2 \mathrm{H}_{\psi}$ is the flux tolerance band and $2 \mathrm{H}_{\mathrm{m}}$ is the torque tolerance band.On the basis of the torque and flux hysteresis status and stator flux switching sector which is indicated by

$\alpha=\left\llcorner\varphi_{s}^{S}=\tan ^{-1}\left(\varphi_{\mathrm{qs}}^{\mathrm{s}} / \varphi_{\mathrm{ds}}^{\mathrm{s}}\right)\right.$

Switching table output is a setting of switching devices of the inverter: hence DTC technique [8] selects the inverter voltage vector to apply the asynchronous machine from table. 2 and Figure 4 shows the relationship between the inverter voltage vector and stator flux switching sector in which six active switching vectors are:

$\mathrm{V}_{1}=\left[\begin{array}{lll}1 & 0 & 0\end{array}\right], \mathrm{V}_{2}=\left[\begin{array}{lll}1 & 1 & 0\end{array}\right], \mathrm{V}_{3}=\left[\begin{array}{lll}0 & 1 & 0\end{array}\right], \quad \mathrm{V}_{4}=\left[\begin{array}{lll}0 & 1 & 1\end{array}\right], \mathrm{V}_{5}=\left[\begin{array}{lll}0 & 0 & 1\end{array}\right]$, $\mathrm{V}_{6}=\left[\begin{array}{lll}1 & 0 & 1\end{array}\right]$ and two zero switching vectors are: $\mathrm{V}_{0}=\left[\begin{array}{lll}0 & 0 & 0\end{array}\right], \mathrm{V}_{7}=$ $\left[\begin{array}{lll}1 & 1 & 1\end{array}\right]$ and also

$0^{\circ}<\alpha(1)<60^{\circ}, 60^{\circ}<\alpha(2)<120^{\circ}, 120^{\circ}<\alpha(3)<180^{\circ}, 180^{\circ}$ $<\alpha(4)<240^{\circ}, 240^{\circ}<\alpha(5)<300^{\circ}, 300^{\circ}<\alpha(6)<360^{\circ}$.

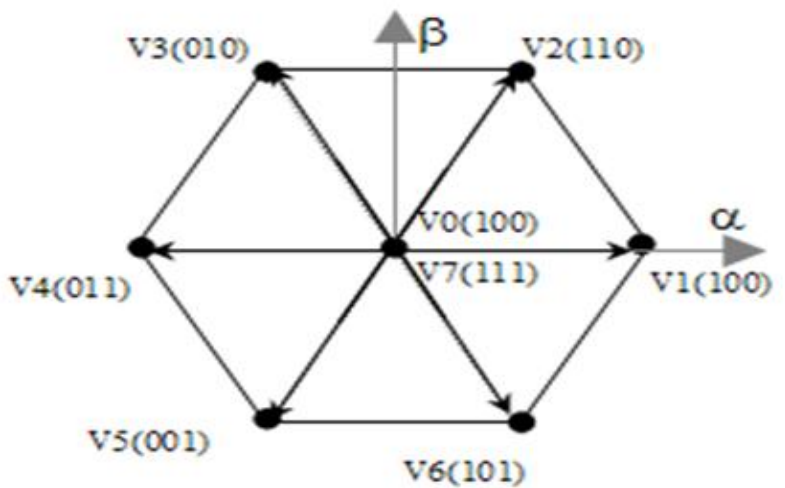

Figure 4: shows switching vectors 
Table .2: switching table of voltage vectors

\begin{tabular}{|c|c|c|c|c|c|c|c|}
\hline $\mathbf{H}_{\psi}$ & $\mathbf{H}_{\mathrm{Te}}$ & $\boldsymbol{\alpha}(\mathbf{1})$ & $\boldsymbol{\alpha}(\mathbf{2})$ & $\boldsymbol{\alpha}(\mathbf{3})$ & $\boldsymbol{\alpha}(\mathbf{4})$ & $\boldsymbol{\alpha}(\mathbf{5})$ & $\boldsymbol{\alpha}(\mathbf{6})$ \\
\hline \multirow{3}{*}{$\mathbf{1}$} & $\mathbf{1}$ & 110 & 010 & 011 & 001 & 101 & 100 \\
\cline { 2 - 8 } & $\mathbf{0}$ & 000 & 111 & 000 & 111 & 000 & 111 \\
\cline { 2 - 8 } & $\mathbf{- 1}$ & 101 & 100 & 110 & 010 & 011 & 001 \\
\hline \multirow{2}{*}{$\mathbf{- 1}$} & $\mathbf{1}$ & 010 & 011 & 001 & 101 & 100 & 110 \\
\cline { 2 - 8 } & $\mathbf{0}$ & 111 & 000 & 111 & 000 & 111 & 000 \\
\cline { 2 - 8 } & $\mathbf{- 1}$ & 001 & 101 & 100 & 110 & 010 & 011 \\
\hline
\end{tabular}

\section{Direct Torque Neuro-Fuzzy Controller}

Neuro-fuzzy systems have become popular in several fields and especially in control. In this kind of controllers, fuzzy logic provides a structure within which the learning ability of neural networks is employed. In this field there are a number of possible uses. In fact, for the ANFIS system (Adaptive Network-based Fuzzy Inference System), neural networks are used to implement a fuzzy inference system such as in "Fig.5". This technique provides at first a neural network to learn information about a data set, in order to compute the membership function parameters that best allow the associated (FIS) to track the given input/output data. Figure.5 shows the block diagram of DTC Neuro-Fuzzy Control (DTNFC) of asynchronous drive. Torque and stator flux are estimated mathematically from the motor signals. ANFIS is used as controller to which the torque and flux error along with position inputs and from which inverter switching states are estimated.A fuzzy logic real time estimator is used as the stator resistance observer, to eliminated the error in rotor resistance estimation. The performance of the asynchronous drive with the above rotor and staotr resistance estimators is investigated for torque and flux responses, to analyze the effects of stator resistance observer on rotor resistance identification for variations in the stator and rotor resistances from their nominal values. Both these resistances are estimated experimetally, in a vector controled induction motor drive and found to give accurate estimates.

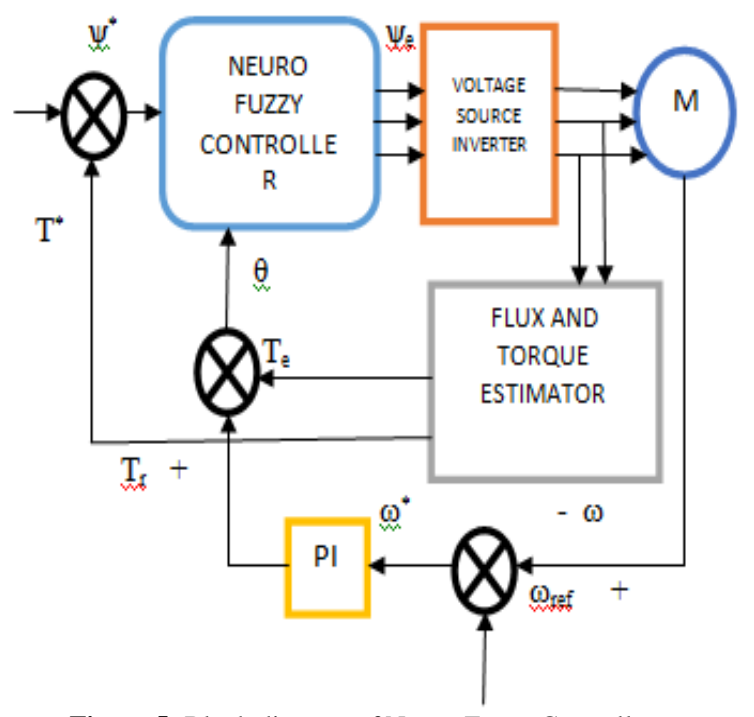

Figure 5: Block diagram of Neuro-Fuzzy Controller

\section{A. STRUCTURE OF ANFIS}

The ANFIS acts exactly as a classical fuzzy inference system type Sugeno in terms of fuzzification, knowledge base and defuzzification. The neural networks are utilized to model and implement the fuzzy inference system; its structure is as shown in figure.5, in built with five layers.

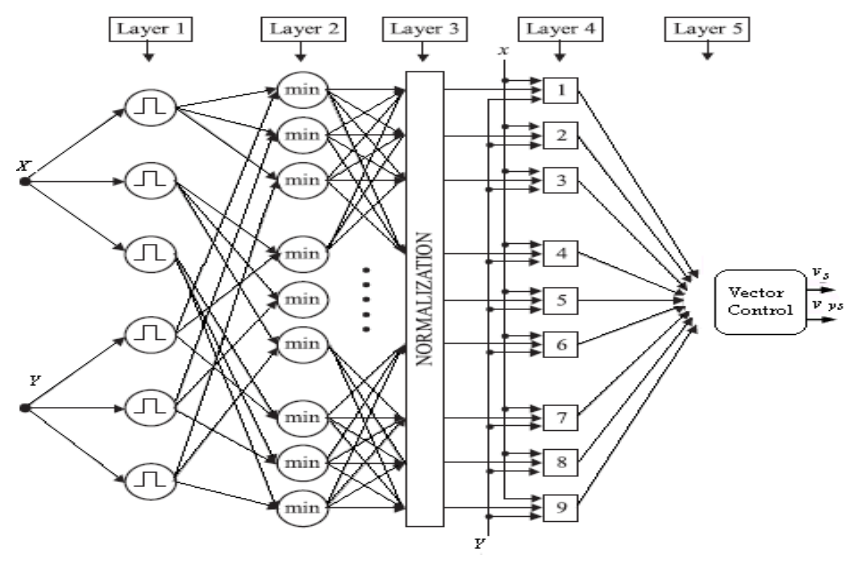

LAYER 1: This layer is composed of a number of computing nodes whose activation functions are fuzzy logic membership functions (triangular or bell shape).

LAYER 2: This layer chooses the minimum value of the inputs.

LAYER 3: This layer normalizes each input with respect to the others (The $\mathrm{i}^{\text {th }}$ node output is the $\mathrm{i}^{\text {th }}$ input divided the sum of all the other inputs).

LAYER 4: This layer's $i^{\text {th }}$ node output is a linear function of the third layer's $i^{\text {th }}$ node output and the ANFIS input signals.

LAYER 5: This layer sums all the incoming signals. [8]

\section{B. SIMULATION RESULTS OF DIRECT TORQUE EURO-FUZZY CONTROLLER}

A proposed ANFIS controller have three variable inputs are the stator flux error $\left(\varepsilon_{\psi}\right)$, electromagnetic torque error $\left(\varepsilon_{\mathrm{T}}\right)$ and angle of stator flux $\left(\theta_{\psi}\right)$ the output is the voltage space vector. [9] In this proposed self tuned DTNFC for a voltage source inverter (VSI) fed induction motor is presented in the internal structure of NFC is shown in figure. 5

In this NFC structure of the first layer the sampled flux error $\left(\varepsilon_{\psi}\right)$, electromagnetic torque error $\left(\varepsilon_{\mathrm{T}}\right)$ and angle of stator flux $\left(\theta_{\psi}\right)$, multiplied by their weights, are each mapped through three fuzzy logic membership functions. These are chosen to be a triangular shapped for all the inputs and it gives good outputs. The second layer determines the minimum error value of three input weights by determining the firing strengths of the rules and given as:

$\mu_{\mathrm{i}}=\min \left(\mu^{\mathrm{i}} \mathrm{A} 1\left(\varepsilon_{\psi}\right), \mu^{\mathrm{i}} \mathrm{A} 2\left(\varepsilon_{\mathrm{T}}\right), \mu^{\mathrm{i}} \mathrm{A} 3\left(\theta_{\psi}\right)\right.$

The third layer calculates the weights which are normalized. Normalized value of the firing strengths is defined as the ratio of the firing strength of the $\mathrm{K}^{\text {th }}$ rule to the sum of the firing strengths:

$\mu_{\mathrm{i}}=\mu_{\mathrm{i}} / \Sigma \mu_{\mathrm{i}}$

The fourth layer containing adaptive node is the defuzzification layer. The output from this layer is:

$\mathrm{O}_{4}=\mu_{\mathrm{i}} \mathrm{f}_{\mathrm{i}}=\mu_{\mathrm{i}}\left(\mathrm{P}_{\mathrm{i}} \mathrm{x}+\mathrm{Q}_{\mathrm{i}} \mathrm{y}+\mathrm{m}_{\mathrm{i}} \mathrm{z}+\mathrm{r}_{\mathrm{i}}\right)$

Where $\mathrm{I}$ is the fourth layer output and $\mathrm{P}=\mathrm{Q}=\mathrm{m}=0$, So the relationship between the inputs and outputs is:

$\mathrm{O}_{4}=\mu_{\mathrm{i}} \mathrm{f}_{\mathrm{i}}=\mu_{\mathrm{i}}\left(\mathrm{r}_{\mathrm{i}}\right)$

The fifth layer consists of a single fixed node; it is the summation of the weighted output layer is given by:

$\mathrm{O}_{5}=\Sigma \mu_{\mathrm{i}} \mathrm{f}_{\mathrm{i}}=\Sigma \mu_{\mathrm{i}} \mathrm{f}_{\mathrm{i}} / \Sigma \mu_{\mathrm{i}}$

According to this NFC method have 72 rules, where the rules used to give appropriate outputs. This switching state of the inverter 
varies from $\mathrm{V}_{0}$ to $\mathrm{V}_{7}$. The output of the ANFIS are crisp value varies from $V_{0}$ to $V_{7}$ to generate three digital logic signals that select the proper switching states of the inverter by using logical operation depending upon the table. [9]

\section{SIMULATION RESULTS OF DTNFC}

In MATLAB the ANFIS editor GUI is available in fuzzy logic tool box, using a given

inputs and output data set, the tool box constructs a FIS. [9]

Whose membership function parameters are adjusted using either a propagation algorithm alone, or in a combination with least squares method. The table shows the comparison table for different intelligent controllers with conventional PI controllers. The simulation results are shown in figures:

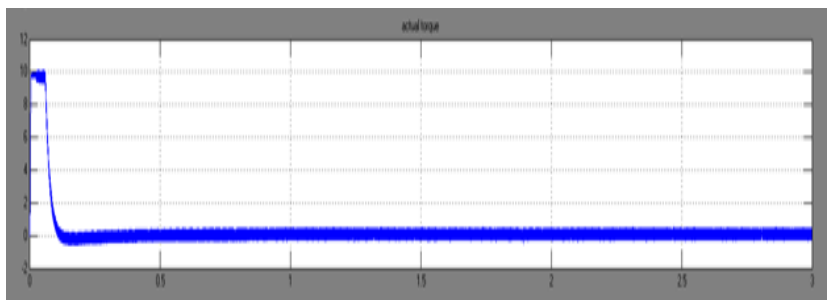

Figure 6: shows the Torque characteristics at No-load with PI controller

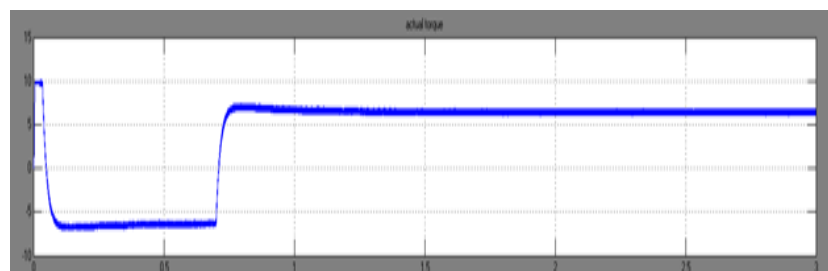

Figure 7: shows the Torque characteristics at change in load with PI controller

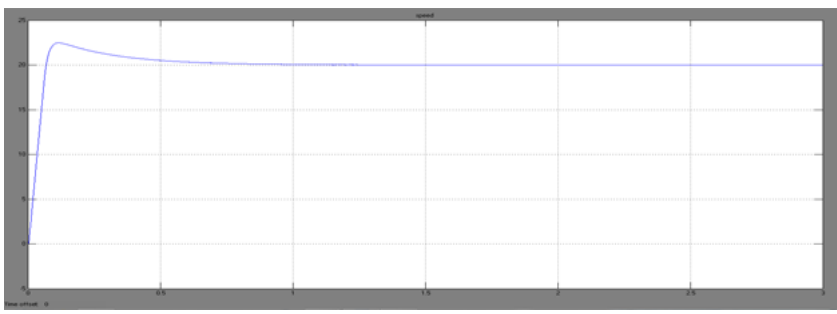

Figure 8: shows the Speed characteristics at No-load with PI controller

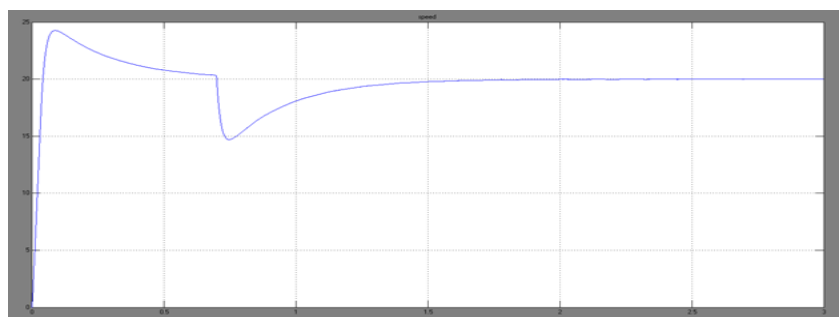

Figure 9: shows the Speed characteristics at change in load with PI controller

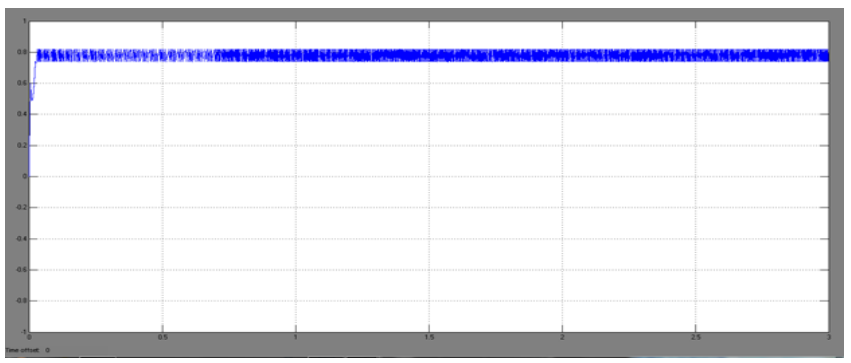

Figure 10: shows the Stator flux response with PI controller

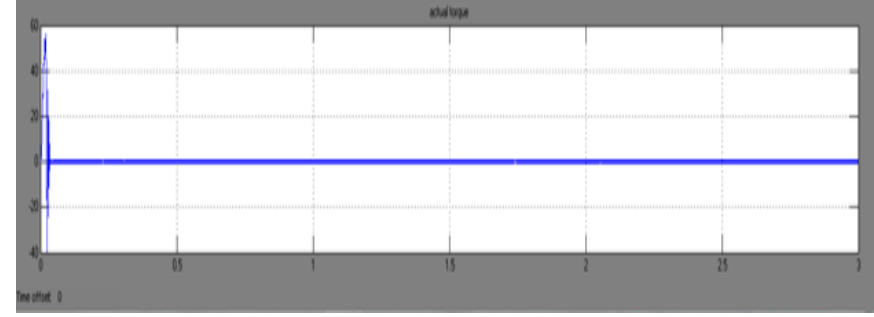

Figure 11: shows the Torque characteristics at No-load with Neuro-fuzzy controller

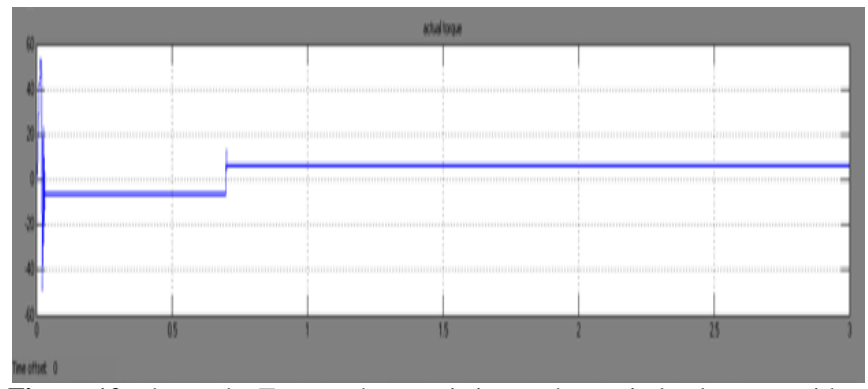

Figure 12: shows the Torque characteristics at change in load torque with Neuro-fuzzy controller

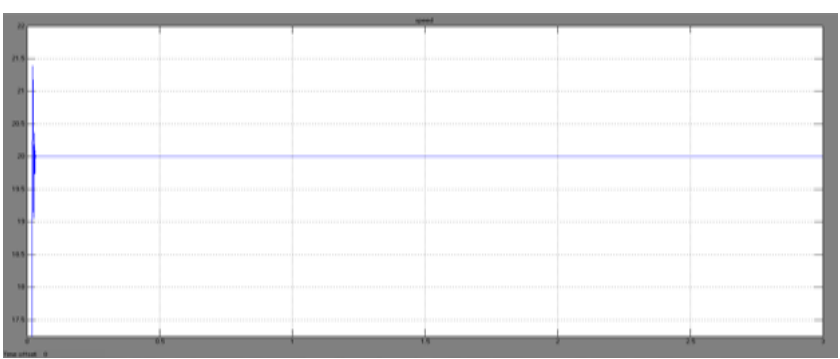

Figure 13: shows the Speed characteristics at No-load with Neuro-fuzzy controller

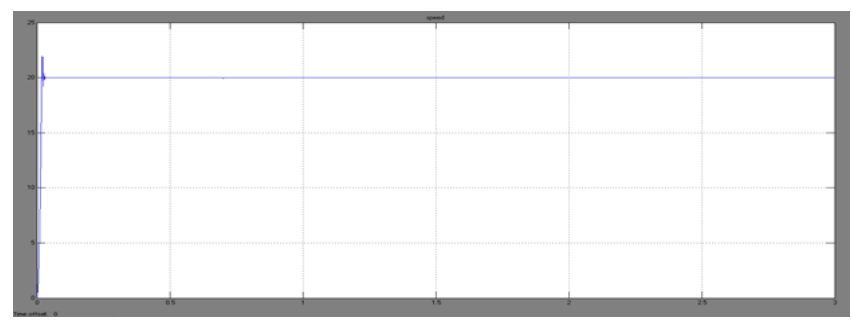

Figure 14: shows the Speed characteristics at change in load with Neurofuzzy controller

Comparison table:

Table1: shows the comparison of different controllers

\begin{tabular}{|c|l|l|l|l|l|}
\hline $\begin{array}{l}\text { SL. } \\
\text { NO. }\end{array}$ & PARAMETERS & PI & FLC & ANN & NFC \\
\hline 1 & FLUX RIPPLE $(\%)$ & 3.75 & 3.25 & 3.0 & 2.3 \\
\hline 2 & $\begin{array}{l}\text { TORQUE RIPPLE } \\
(\%)\end{array}$ & 13.3 & 9.2 & 7.1 & 3.5 \\
\hline 3 & OVER SHOOT $(\%)$ & 47 & 32 & 30 & 7 \\
\hline 4 & $\begin{array}{l}\text { COMPUT ATIONAL } \\
\text { EFFORTS }(\mu \text { sec) }\end{array}$ & 21.6 & 50 & 42 & 91.2 \\
\hline 5 & THD $(\%)$ & 11.56 & 3.56 & 3.62 & 2.78 \\
\hline
\end{tabular}

\section{Conclusion}

Direct torque control (DTC) of induction motor gives optimal performance of drive systems in steady state as well as under transient conditions. DTC achieves precise speed and torque control of induction motor and make it compatible for applications where smooth and fine control of drive is essential. We have implemented Direct Torque Neuro Fuzzy Controller (DTNFC) for 
Induction Motor with three level inverter. Neural Network means for synthesizing a controller from engineering experiences that can be more robust, have better performance, and reduce cycle times due to the multilayer feed forward network. It is concluded that despite of their simple control structure the proposed Neuro fuzzy controllers have managed to significantly reduce the torque and flux ripples. As we introduce the Neuro-fuzzy control to conventional DTC, the advantages of comparing the other AI techniques are as: Simple architecture and easy implementation, easy to evaluate, easy and to it improves the torque and flux ripple of Induction Motor. For future work we go to use in addition to use some combined AI techniques to improve the performance.

\section{Acknowledgment}

This research is made under the guidance of Dr.A.Sivasubramanian (Principal) in Mount Zion College of Engineering, Pathanamthitta, and Kerala. I, V. Sakthi (research scholar/EEE SCSVMV University, Kanchipuram, India) would like to thank my guide and my family members \& my dear friends for helping me in this research and for their guidance and constant encouragement towards the work.

\section{References}

[1] Bose, B.K., 1996. Power electronics \& variable frequency drives, IEEE pres, New York.

[2] Takashi, I., T. Naguchi, 1986. "A new quickresponse and highefficiency control strategy of induction motor", IEEE Trans, On 22(5):820-827.

[3] Takashi and Y. Ohmori, 1989. "High performance DTC of an induction motor", IEEE Trans. On industry applications, 25(2): 14-18.

[4] Pujol, A.A., 2000. "Improvement in direct torque control of induction motors", These de doctorat de L'UPC.

[5] Toufouti, R., S. Meziane, H. Bemalla, 2006. "Direct torque control for induction motor using Fuzzy Logic", ICGST Trans. On ACSE, 6(2): 17-24

[6] Mokrani, L., R. Abdessemed, 2003. A fuzzy self- tuning PI controller for speed control of induction motor drive, in: Proceedings of the IEEE Conference on control applications Piscataway, NJ, USA, pp: 785-790.

[7] Lai, Y., J. Lin, 2003. New hybrid fuzzy controller for direct torque control of induction motor drives, IEEE Trans, Power Electron, 18:1211-1219.

[8] Baburaj Karanayi, and Muhammed Fazlur Rahman, 2005 "Stator and Rotor resistance observers for induction motor drive using fuzzy logic and Artificial neural networks," IEEE Trans. J.Energy Convers., 20(4): 771-780.

[9] Jang, J. 1996. ANFIS: adaptive network-based fuzzy inference systems. IEEE, Trans. Syst. Nan cybern, 23: 665-85.

[10] P. Vas, "Artificial-intelligence-based electrical machines and drives", New York: Oxford Univ. Press, (1999). 